\title{
Move it for shade!
}

\author{
Christoph Paech* \\ * schlaich bergermann partner \\ Schwabstrasse 43, 70197 Stuttgart, Germany \\ e-mail: c.paech@sbp.de, web page: http://www.sbp.de
}

\begin{abstract}
Retractable lightweight structures with textile membranes increase the functionality of a building significantly. An adaptive building envelope transforms a stadium within minutes into a multifunctional arena, improves the interior climate, comfort and general acoustics.

The Al Janoub Stadium in Qatar features a $10.800 \mathrm{~m}^{2}$ innovative retractable membrane roof. The layout of the retractable roof has been developed to perfectly fit to the overall architectural appearance of the building. Within 30 minutes the retractable roof can be closed to provide full shade for the playing field and the stands, which is essential in areas with strong solar radiation to reduce the temperature and to provide the desired spectator comfort. The stadium is located in the port city of Al Wakrah, south of Doha. The intention is to host over 40,000 spectators during the FIFA 2022 Worldcup. Being one of the oldest cities in Qatar, Al Wakrah used to be the starting point for the traditional Dhow fishing and pearl boats. The striking hull of a dhow with its large sails inspired Zaha Hadid Architects to create such futuristic design. The roof support structure resembles the skeleton of ship frames, surrounded by a roof skin with gracefully curved surfaces and folds, interpreting the waters of the Persian Gulf.
\end{abstract}

The inner retractable roof above the field of play measures approximately $170 \mathrm{~m}$ in north-south direction and up to $93 \mathrm{~m}$ in east-west direction. The elegant concept for the inner roof is very efficiently based on lightweight construction principles. Low-mass and high-strength materials significantly reduce the consumption of resources. Most elements are only axially utilized in tension so the crosssections can be minimalized resulting in a very elegant appearance.
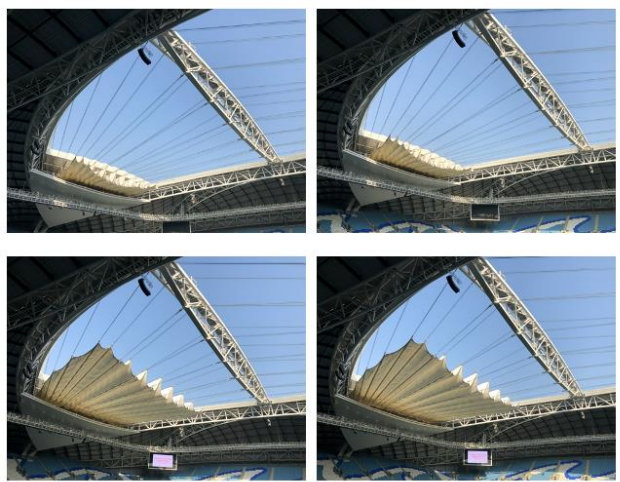
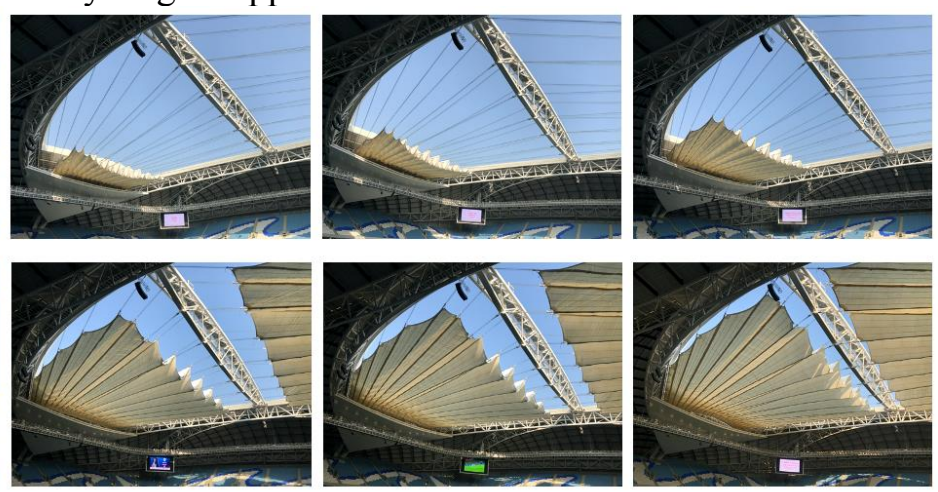

${ }^{\odot}$ schlaich bergermann partner / Christoph Paech

The innovative design of the retractable membrane roof of the Al Janoub stadium is one more example how the integration of adaptive building components increase the possibilities of usage of a building as it has been also proven for previous projects as for example the BC Place Stadium in Vancouver or the retractable roof of the Stadium in Frankfurt. Hence even more spectacular projects with retractable membrane elements will follow in the future.

\section{REFERENCES}

[1] C. Paech, Moveable membranes - smart solutions in the field of architecture. Proceedings of the TensiNet Symposium 2019.

[2] Göppert, K., Moschner, T., Paech, C., Stein, M., Werner, M., Die Krone von Vancouver Erneuerung des BC Place Stadions. Stahlbau 81 (2012), H. 6, page 457-462. 